\title{
Effect of heat treatment on the microstructure and mechanical properties of a low-carbon X80 pipeline steel
}

\author{
B.C. Acosta-Cinciri ${ }^{1}$, N.M. López-Granados ${ }^{1, *}$, J.A. Ramos-Banderas ${ }^{1}$, C.A. Hernández-Bocanegra ${ }^{1,2}$, \\ P. Garnica-González ${ }^{1}$, J.A. López-Corpus ${ }^{3}$ \\ ${ }^{1}$ TecNM/I.T. Morelia, Tecnológico 1500 Av., 58120, Morelia, Michoacán, México \\ ${ }^{2}$ CÁTEDRAS-CONACYT, Insurgentes Sur 1528 Av., 03940, CDMX, México \\ ${ }^{3}$ AHMSA, Juárez Av., 25770, Monclova, Coahuila, México
}

\begin{abstract}
In this work, the effect of heat treatment conditions on the microstructure and mechanical properties of an American Petroleum Institute (API) X80 steel with a low carbon content of $\sim 0.02 \%$ wt., destined for the manufacture of pipelines and pipeline transmission systems by welding, was investigated. Samples were heat treated under different conditions and then were characterized by scanning electron microscopy (SEM), orientation image microscopy (OIM), and electron backscattered diffraction (EBSD). The results showed that when the steel is fastly cooled from the austenitic field $\left(990^{\circ} \mathrm{C}\right)$, the mechanical properties increase significantly [ultimate tensile strength (UTS) $>1,100 \mathrm{MPa}$, yield strength (YS) $900 \mathrm{MPa}$, and elongation $27 \%$ ] due to the high percentage of martensite (M) present in the microstructure (95\%). In contrast, when the cooling rate decreases and the treatment conditions remain at/or above the bainitic/martensitic transformation (from $990^{\circ} \mathrm{C}$ to $600^{\circ} \mathrm{C}$ and $450^{\circ} \mathrm{C}$ ), the mechanical properties are decreased by almost $50 \%$ because of the decrease in the percentage of martensite $(18 \%)$. However, the percentage of elongation increases significantly (38\%) due to the presence of other micro-constituents resulting from the phase transformation. On the other hand, the best combination of mechanical properties (UTS above 800 MPa and YS between $610 \mathrm{MPa}$ and $720 \mathrm{MPa}$ ) was obtained when the steel acquired a dual-phase microstructure [(martensite/austenite)(ferrite/martensite)] since the amount of martensite is conserved between $45 \%$ and $82 \%$, in combination with the other microconstituent present in the steel that allows us to achieve elongation percentages close to $30 \%$.
\end{abstract}

Keywords: X80 steel, microstructure, mechanical properties, IQ, EBSD

\section{Introduction}

Actually, X80 steels produced under the American Petroleum Institute (API) standard have received great importance due to their ability to withstand large loads and pressures with the highest possible efficiency in companies which manufacture oil and gas transmission pipes [1]. The combination of superior strength properties and excellent toughness of X80 grade is obtained by chemical composition design and controlled thermomechanical processing [2]. Certainly, the modification in the processing conditions can lead to the formation of multi-phase microstructures such as polygonal ferrite, pearlite, bainite, and martensite that result in a great diversity of mechanical proper-

*E-mail: nancy.lg@morelia.tecnm.mx ties. The use of high finishing temperatures during rolling in combination with low cooling rates in X70 steel leads to the formation of microstructures composed of polygonal ferrite, Widmanstätten ferrite, acicular ferrite, etc., which considerably decrease toughness, while forming phases such as bainitic ferrite and martensite, formed at lower finishing temperatures, improve it considerably [3]. On the other hand, processing under controlled rolling conditions and accelerated cooling has been used to produce steels with phases such as martensite and bainite since they significantly increase microhardness, resistance, and yield stress [4]. Additionally, the modification of the chemical composition in these steels has given good results due to the generation of phases such as acicular ferrite, which provides good resistance and toughness properties [5]. Actually, various analysis and modeling tech- 
niques have made it possible to establish correlations between mechanical properties and chemical composition [6], achieving to predict with excellent accuracy the mechanical behavior of API microalloyed steels [7]. The welding process is the essential subsequent stages in the installation of pipelines, especially when it is required to cover long distances for the transportation of oil and gas [8]. During the conventional welding fusion process, steel - mother pipe - is induced to heating cycles that cause a significant microstructural change and decrease not only the transition temperature but also the tensile strength below the standard requirements. One of the most important constituents in line pipe steels is the martensite-austenite (M/A) micro-constituent in combination with structures formed by ferrite-bainite because it has a relevant effect on the thermally affected zone when they are subjected to different cooling rates during the welding processes [9]. However, it reduces the elastic ratio and toughness [10]. One way to confront these problems consists in applying a heat treatment before the welding process to obtain a microstructure, which can increase the required ultimate tensile strength (UTS) for this type of application that guarantees this property in a posterior process [11]. However, the use of heat treatments involves phase transformation processes, where each of the austenite decomposition products is a function of the cooling rate employed, which can lead to the formation of microstructures with a variety of micro-constituents [12]. Conventional characterization techniques are normally based on the visualization of morphology by using optical microscopy (OM) and scanning electron microscopy (SEM). These methods allow the identification of the constituents in simple microstructures; however, these techniques fail for mixtures of microconstituents, i.e., mixtures of ferrite with different morphology or bainite/martensite [13]. Recently, the electron backscattered diffraction (EBSD) technique has been used as a tool for identification and quantification phases, taking advantage of the image quality (IQ) values that are produced by the difference between the crystallographic structure generated by the cooling rate of the resulting decomposition products [14]. This research shows an experimental technique for the design and application of different heat treatment conditions on an API X80 steel with low carbon content, as well as the evaluation and effect of the amount and type of micro-constituents generated on the mechanical properties. The phase transformation products were analyzed qualitatively and quantitatively by multi-modal separation processing of the IQ data obtained from the EBSD characterization.

\section{Experimental procedure}

An API X80 low-carbon commercial steel under rolling conditions was employed, with $20-\mathrm{mm}$ thickness and a yield point of $600 \mathrm{MPa}$. Table 1 shows the chemical composition determined by optical emission spectroscopy based on the American Society for Testing and Materials (ASTM) E-403 standard. The critical transformation temperatures Ac1 and Ac3 were determined by dilatometric analysis whose values were $940^{\circ} \mathrm{C}$ and $715^{\circ} \mathrm{C}$, respectively.

Based on this information, five experimental thermal treatments (TT1-TT5) were designed as shown in Figure 1, which consist of heating to the austenitic region, $990^{\circ} \mathrm{C}$, subsequently a period of permanence at this temperature for $12 \mathrm{~min}$, followed by different cooling conditions. In TT1, the quenching was carried out in water until room temperature; in TT2, the cooling was carried out until $450^{\circ} \mathrm{C}$ in a salt bath with a residence time of $3 \mathrm{~min}$, to later cool in air up to room temperature; in TT3, the cooling was carried out until the beginning of bainitic transformation, remaining at this temperature for $3 \mathrm{~min}$, then it was cooled to reach the beginning of the martensitic transformation, where it was kept for $3 \mathrm{~min}$ and finally leaded to environmental temperature; the TT4 was based on the treatment to obtain dual-phase steels and consisted of cooling up to the intercritical range, with a holding time of $3 \mathrm{~min}$, followed by cooling in water to room temperature; and the TT5 called quenching and partition treatment, cooling was carried out in water from the austenitic field to reach room temperature, followed by reheating above the beginning of martensitic transformation temperature -Ms-, maintaining for $3 \mathrm{~min}$ and subsequent cool- 
Table 1. Chemical composition, \% wt.

\begin{tabular}{lcccccccccc}
\hline $\mathrm{C}$ & $\mathrm{Mn}$ & $\mathrm{P}$ & $\mathrm{Si}$ & $\mathrm{Cu}$ & $\mathrm{Cr}$ & $\mathrm{Ni}$ & $\mathrm{Mo}$ & $\mathrm{V}$ & $\mathrm{Nb}$ & $\mathrm{Ti}$ \\
\hline \hline 0.02 & 1.621 & 0.0097 & 0.332 & 0.026 & 0.29 & 0.29 & 0.014 & 0.036 & 0.086 & 0.024 \\
\hline
\end{tabular}

ing to room temperature. The heat treatment conditions used were selected to produce different types and amounts of micro-constituents.

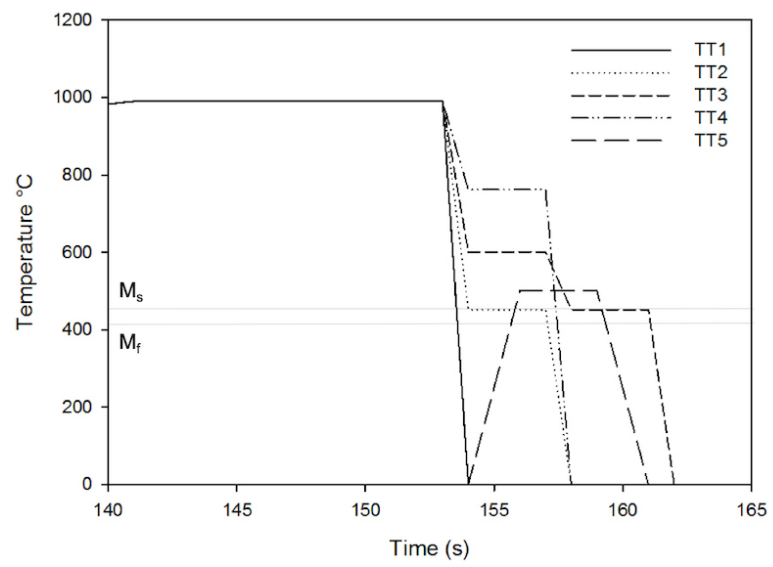

Fig. 1. Schematic diagram of the heat treatments performed on steel. TT, thermal treatment.

Figure 2 shows the continuous cooling transformation (CCT) diagram calculated through the JMat-Pro ${ }^{\circledR}$ program for the steel studied, in which the critical transformation temperatures can be observed, as well as the cooling rates necessary to produce different types of micro-constituents. Some researchers [14] show that in X80 steels, the cooling conditions necessary to obtain the optimal microstructural characteristics are established in the range of cooling rates between $100^{\circ} \mathrm{C} / \mathrm{s}$ and $10^{\circ} \mathrm{C} / \mathrm{s}$.

In this work, five samples of $3 \times 3 \times 1.1 \mathrm{~mm}$ were cut, which were machined and heat treated in a rapid induction thermal analysis (RITA) L78 model dilatometer to generate the desired microconstituents. Subsequently, 15 specimens were machined for mechanical tests according to the ASTM E8/E8M-09 standard with the objective of carrying out reproducibility tests which were heat treated in a type muffle furnace. To have a strict control of the temperature during the thermal cycle, a test

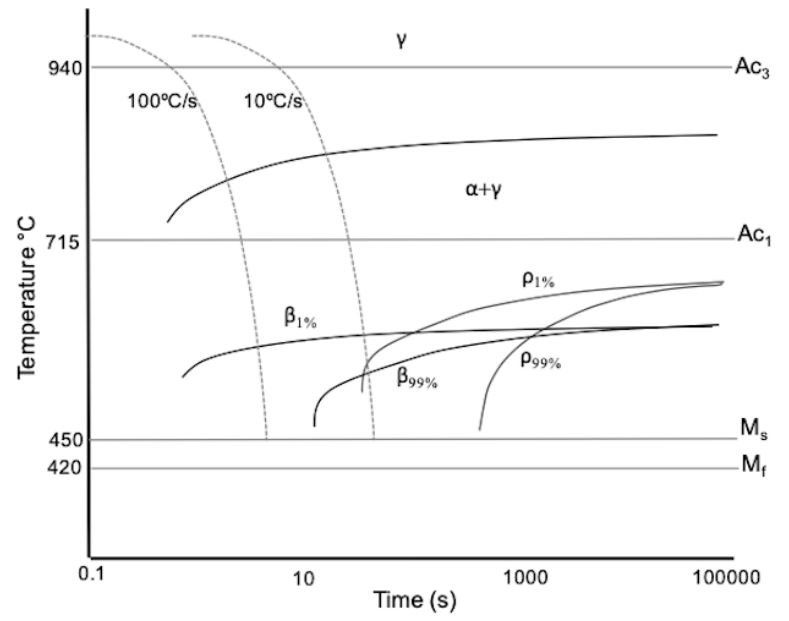

Fig. 2. CCT diagram of the steel studied, calculated by means of the JMat-Pro ${ }^{\circledR}$ program. $\rho=$ pearlite, $\beta=$ bainita. CCT, continuous cooling transformation.

specimen was instrumented with a type K thermocouple. The thermocouple reading was recorded by means of data acquisition system FLUKE model 2680. The mechanical tests were carried out in an INSTRON 1995 universal testing machine; three specimens were analyzed for each of the heat treatments performed, and their results were averaged. Finally, the microstructural analysis was carried out using SEM in a JEOL microscope model JSM5910LV. Samples of $10 \times 10 \times 5 \mathrm{~mm}$ dimensions were cut from both the initial steel and the heat-treated specimens, which were prepared by conventional metallography techniques and etched with a $3 \%$ solution of nital for 20 s. Samples for EBSD analysis were polished with $1 \mu \mathrm{m}$ diamond paste and with $0.04 \mu \mathrm{m}$ colloidal silica for $15 \mathrm{~min}$. During the measurements, the data were collected and processed using the Bruker ${ }^{\circledR}$ program. The IQ values of EBSD patterns acquired by the EBSD analysis were statistically processed by applying the multi-modal distribution method with the help of a spreadsheet for the phase quantification [15]. 


\section{Results and discussion}

\subsection{Effect of the cooling rate on the mi- crostructure}

Figure 3 shows the dilatometry graphs obtained for the five heat treatments. For each heat treatment, when the phase transformation takes place under conditions of continuous heating, the relative change in length recorded in the dilatometric curve is the result of two effects: the intrinsic thermal expansion of the material and the dimensional change associated with the transformation. Figure 3 shows a linear behavior with a constant and positive slope at different temperatures before any transformation takes place. When the austenitizing temperature is reached and as the transformation progresses, the slope undergoes an alteration due to the longitudinal change that occurs in the crystal structure during phase transformations.

Figure 4A shows the microstructure corresponding to the initial steel, which is constituted of a homogeneously distributed ferritic matrix with non-uniform grain size, and some regions with small grains resulting from the recrystallization process. SEM analysis in the recrystallized regions shows the presence of fine islands of microconstituent MA located at the triple junction of ferrite grains, at the grain boundary regions, and even inside the ferrite grains, with both fine and slender block structures (see Figure 4A). However, the analysis performed by this technique did not allow the identification of another type of microconstituent or phases of interest such as bainite. Recent studies [16] indicate that steels with microstructures composed of ferrite and bainite in combination with micro-constituent MA raise the yield point of steel, in addition to causing an important effect on thermally affected zones when steel is subjected to different cooling rates during welding processes [17]. In Figure 4B, the photomicrograph corresponding to TT1 is shown; it can be seen that the microstructure is entirely constituted by the martensite phase, which presents lath-like morphology characteristic of tempered steels. In contrast, in Figure 4C corresponding to TT2, the microstructural analysis shows different reliefs, where some grains with low gray contrast are observed, in addition to small areas with plate morphology belonging to the martensite phase. According to Figure 1 , the designed heat treatment involves a microstructure composed mainly of ferrite, martensite, and small amounts of bainite, of which only the first constituents can be seen in the image due to the similarity in morphology. Additionally, the presence of other phases is shown since the cooling temperature is very close to the intercritical range, while the cooling rate is very low, which would warn of the presence of other micro-constituents such as pearlite. However, due to the complexity of the microstructure, it is necessary to use another method that allows the identification and quantification of all the constituents. On the other hand, in Figure 4D, the microstructure referring to TT3 is showed. According to Figure 1, this treatment was proposed to obtain a steel composed with bainite and martensite phases distributed in a ferritic matrix. The Figure 4D clearly shows a ferritic matrix and combination with martensitic regions; however, the bainite cannot be identified based only on its morphology. Figure 4E exhibits the photomicrograph corresponding to the TT4 projected to obtain a dual-phase steel. In the image, two areas can be seen: a dark regions which evidently belongs to the ferritic matrix and light regions constituted by martensite. Finally, in Figure 4F, the resulting microstructure of the TT5 is shown, which suggests that the resulting microstructure must be constituted of martensite and retained austenite [18]. According to the analysis of the microstructure, the presence of martensite can be clearly appreciated; however, austenite is difficult to identify by this characterization technique.

\subsection{Phase quantification by IQ-EBSD}

When steel is heat treated, the diversity of micro-constituents that are produced during continuous cooling from the austenitic field strongly depends on the cooling conditions used. Microstructural analysis of transformation products by OM (Optical Microscopy) and SEM is carried out by observations based only on morphology. When transformation products result in one or two phases, qualitative and quantitative analy- 
a)

b)

c)

d)

e)

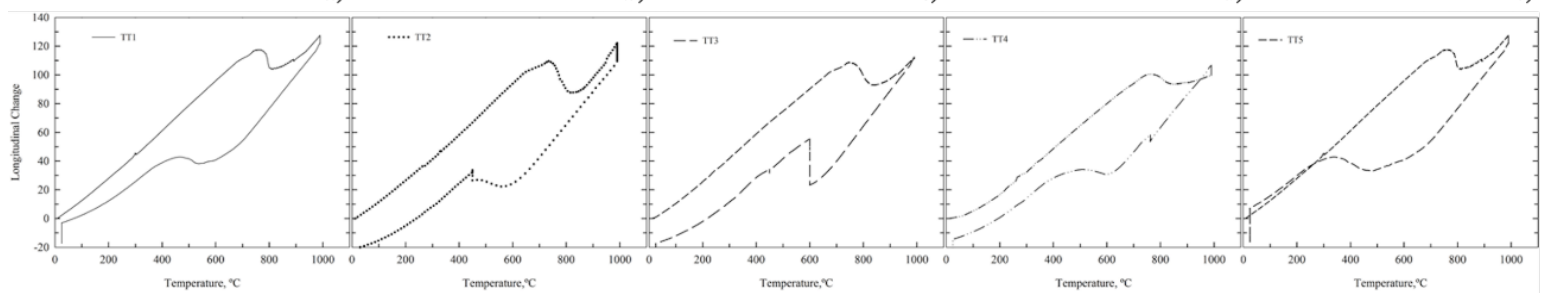

Fig. 3. Dilatometry curves obtained for thermal treatments made in RITA. (A) TT1, (B) TT2, (C) TT3, (D) TT4, and (E) TT5. RITA, rapid induction thermal analysis.
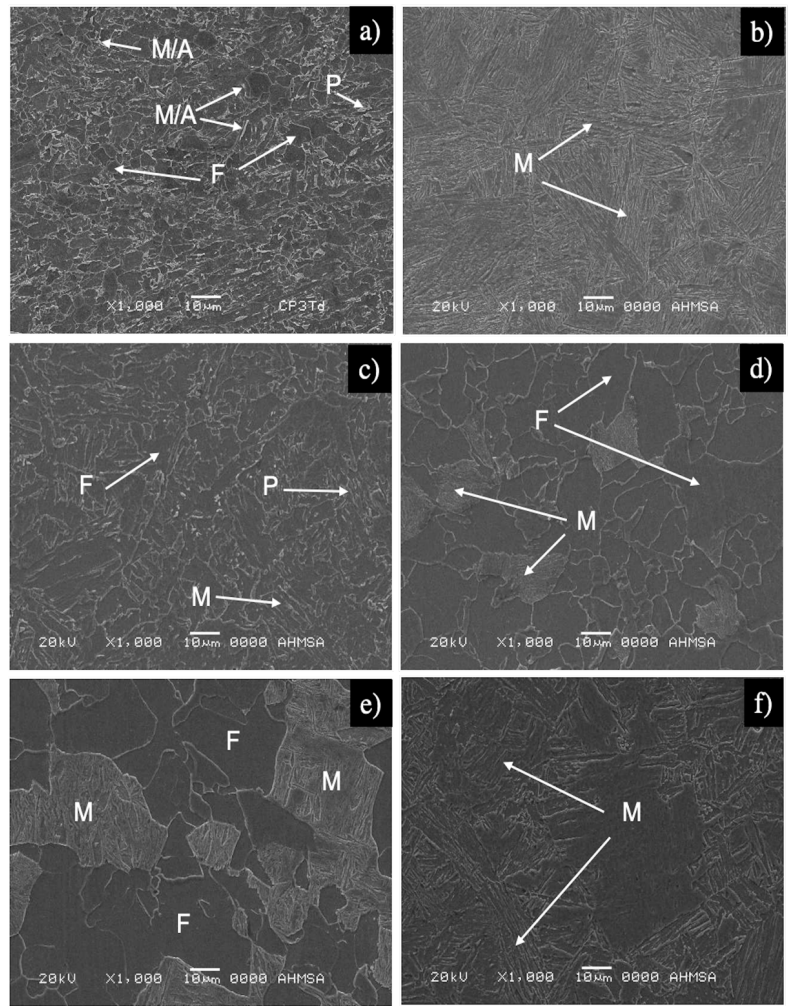

Fig. 4. Photomicrographs obtained by SEM. (A) Untreated steel, (B) TT1, (C) TT2, (D) TT3, (E) TT4, and (F) TT5. F, ferrite M; martensite; MA, martensite/austenite; $P$, pearlite, SEM, scanning electron microscopy; TT, thermal treatment.

ses can easily be carried out. On the other hand, if heat treatment results in a large number of phases and micro-constituents, the analysis becomes more complicated, and the distinction among phases (e.g., ferrite with different morphologies: polygonal, non-polygonal, allotriomorphic ferrite, Widmanstätten ferrite, and intergranular idiomorphic ferrite) can lead to errors. Some researchers have used the EBSD technique [19], recrystallization studies [20], and grain size distribution measurement [21] for texture calculations. Derived from the EBSD texture measurements, a set of values called the IQ index is originated, which is related to the number of accumulated dislocations in the crystal structure during phase transformation [27]. The IQ evaluates the intensity of the Kikuchi patterns. It is based on the intensity of the peaks in Hough space. These peaks represent the intensity distribution with which the Kikuchi bands are detected. For a material with low-density crystalline defects, for example, recrystallized, the intensity of the Kikuchi bands is very high, and, therefore, the diffraction pattern acquires a high intensity and a high IQ value. In contrast, when there are defects (e.g., deformed material), the intensity of the Kikuchi bands is low; therefore, a low IQ value is obtained. IQ is a direct measure of the intensity of the Kikuchi bands that determine the quality of the backscattered electron patterns [22]. Since defects and distortions in the crystal structure in the diffraction volume can significantly affect the intensity of the Kikuchi bands, the IQ values are also related to the structural characteristics of the crystal lattice. In general, dislocations accumulate at the grain boundaries, sub-grains, or inside of the grains that result in a lattice curvature; therefore, it allows us to develop correlations with the deformation resulting from the phase transformation in polycrystalline materials [23]. These characteristics allow the use of IQ as a tool in the characterization of microstructures [24]. A series of IQ maps obtained from the EBSD analysis (Figure 5A-E) and their corresponding distribution curves (Figure 
$5 \mathrm{~A}^{\prime}-\mathrm{E}^{\prime}$ ) calculated by IQ processing data through a statistical separation method [25] are shown for the five heat treatments. For TT1, the IQ image does not show variations in the gray contrast, which indicates that the microstructure is only conformed of one phase, which is in accordance with that shown in Figure 4B. On the other hand, the calculated distribution curve indicates that the highest percentage (94.48\%) corresponds to martensite, while the remaining percentage is associated with large-angle boundaries, grain boundaries, and carbide precipitation. It is important to consider that the phase transformation from austenite to martensite takes place at high cooling rates, which implies distortion in the crystalline structure in addition to the accumulation of a large number of lattice defects. Therefore, it is evident that the IQ values obtained from the measurement are low when it comes to this micro-constituent. The IQ image for TT2 exhibits important variations in the gray scale, which is related to the presence of different types of micro-constituents produced by the heat treatment conditions used. The multimodal distribution results show the presence of four independent normal curves, which correspond to $42.5 \%$ ferrite, $25 \%$ pearlite, $21.25 \%$ bainite, and $11.25 \%$ martensite. The constituents occupy the IQ normalized value range according to the degree of crystalline distortion produced by the phase transformation. The transformation from austenite to ferrite and/or pearlite does not generate high distortion in the crystal lattice, so the IQ values obtained from the analysis are high. However, the transformation from austenite to bainite and martensite produces a large accumulation of crystalline defects and lattice distortions, so their IQ values are set at lower positions on the IQ scale. The IQ analysis performed for the TT3 shows variations in the gray contrast, which indicates the presence of different micro-constituents; this result agrees satisfactorily with the distribution graphs shown in Figure $5 \mathrm{C}^{\prime}$, where it is observed that the percentage of the constituents corresponds to ferrite $(59.09 \%)$, bainite $(22.73 \%)$, and martensite $(18.18 \%)$. The location of the constituents in the IQ normalized data range is located according to the phase transformation kinetics associated with the cooling rates em- ployed. The IQ image for two TT4 contrasting areas is clearly seen: a ferritic constituent (light region) and martensite islands (dark region) homogeneously distributed in the matrix. Consequently, the two distribution peaks or curves corresponded to ferrite and martensite, with $55 \%$ and $45 \%$, respectively. Finally, for TT5, the IQ image presents low contrast in almost the entire image. However, the result of the separation of the distribution curve notices the presence of two normal curves which are associated with the ferrite and retained austenite phases as a result of the design of this heat treatment.

\subsection{Mechanical property analysis}

The results obtained from the stress vs. strain curves of the heat-treated samples are shown in Figure 6. According to the API-5L standard for grade X80 and higher, the mechanical properties obtained after applying the heat treatment accomplish the necessary requirements, which establish a UTS value of $600 \mathrm{MPa}$ as a minimum. In the graph, it can be seen that the best properties of UTS correspond to TT1 since the UTS is $>1,100$ MPa. However, TT3 and TT4 present the lowest UTS results, in contrast to the high percentage of deformation obtained $(40 \%)$, due to the treatment conditions used. This behavior is associated with the presence of martensite since $95 \%$ of the structure is composed of this phase; therefore, it represents the appropriate treatment when desired and elevates such properties.

A complete summary of the effect of heat treatment on mechanical properties and its relationship with martensite content is presented in Figure 7. In the case of the TT1, it not only presents the highest values of UTS but also presents the yield strength (YS) (900 MPa). This behavior is associated with the presence of martensite since $95 \%$ of the structure is composed of this phase, therefore, it represents the appropriate treatment when what is required is to raise such properties. However, this microstructure is not suitable since it has high hardness and low ductility for a welding process; the steel resulting from this treatment generated a microstructure composed of tempered martensite, 
a)

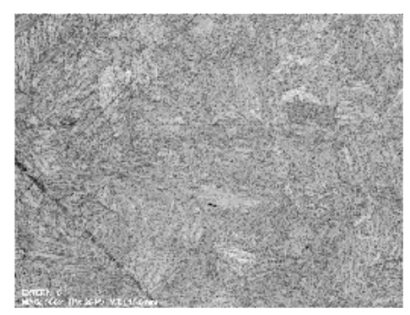

b)

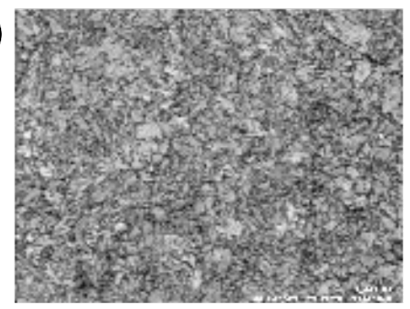

c)

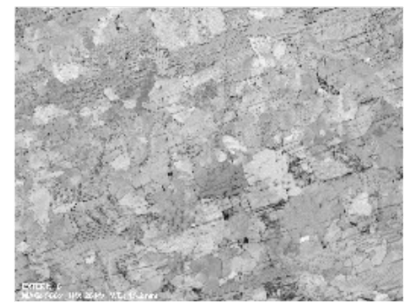

d)

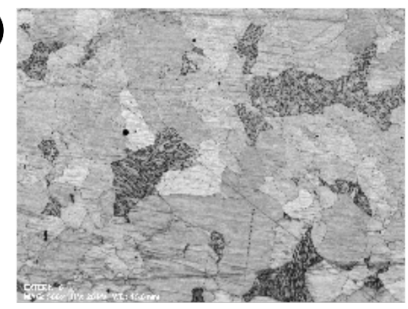

e)

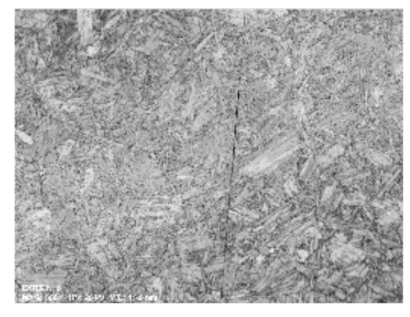

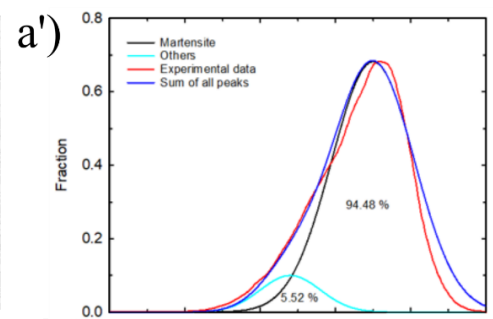

$\left.b^{\prime}\right)$

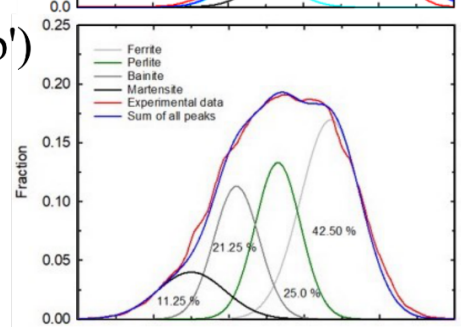

c')

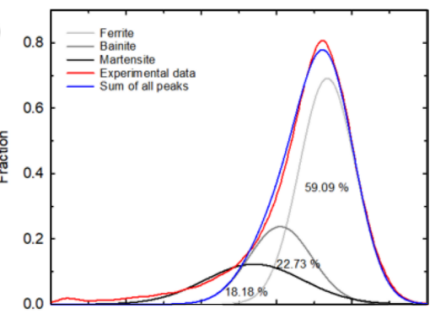

d')

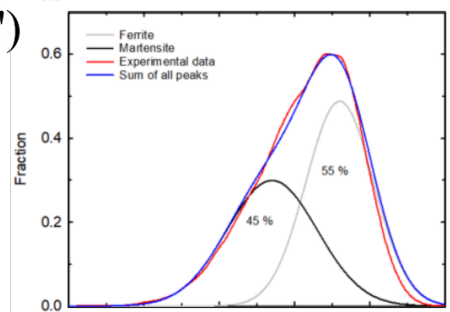

$\left.e^{\prime}\right)$

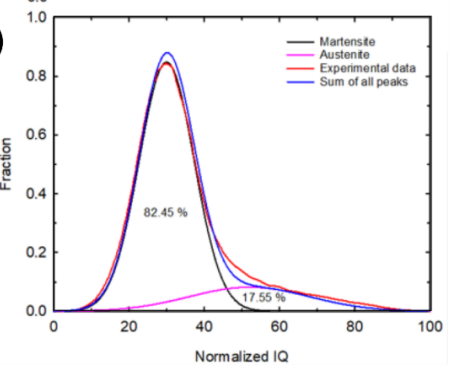

Fig. 5. IQ quality index maps (left) and distribution curves obtained by statistical separation (right) for heat-treated steel: (A) TT1, (B) TT2, (C) TT3, (D) TT4, and (E) TT5. IQ, image quality; TT, thermal treatment.

consequently decreasing the tensile strength and hindering any operation given the hardness of the phase. Otherwise, it could improve other properties such as percentage elongation and ductility, that is, the mechanical behavior would be similar to that of TT5, which resulted in a double-phase microstructure that gives the steel excellent mechanical properties. In Figure 7, in the region corresponding to
TT5, it can be seen that the values of UTS and YS are $810 \mathrm{MPa}$ and $720 \mathrm{MPa}$, respectively. In contrast, due to the amount of martensite present in the steel $(82 \%)$, it causes the percentage of deformation to decrease considerably to $25 \%$. Despite, this treatment - TT5 - would be convenient for two reasons: first, due to the amount of retained austenite, when this material subjected to a reheating pro- 


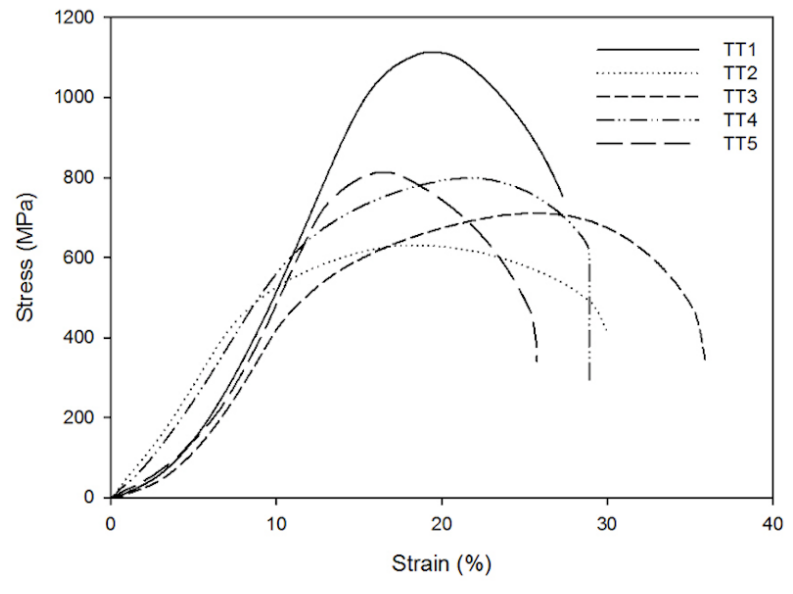

Fig. 6. Averaged stress vs. strain curves obtained for heat-treated steel samples. TT, thermal treatment.

cess, the austenite could decompose into some of the intermediate products, ensuring the prevalence of the required mechanical properties. Second, the martensite resulting from this treatment is of low hardness due to the tempering cycle; therefore, it simplifies the welding stage. Additionally, in Figure 7, it can be seen that the lowest UTS and YS values (620 MPa and $440 \mathrm{MPa}$, respectively) were obtained for the sample subjected to TT2; this is due to the fact that the resulting microstructure is a mixture of micro-constituents, where some of these improve resistance, as in the case of martensite (11\%), while the ferrite found in the steel provides major ductility increasing the percentage of deformation above $30 \%$, though other constituents such as pearlite counteract the effect caused by the previous ones. On the other hand, the best percentages of deformation correspond to TT3 ( 38\%), due to the increase in the content of the ferrite phase, in addition to the presence of bainite and martensite $(>18 \%)$, which produce a significant effect on the UTS and YS, reaching values close to the 700 $\mathrm{MPa}$ and $425 \mathrm{MPa}$, respectively. The resulting microstructure of TT4 corresponds to a dual-phase (ferritic-martensitic) steel. This type of steels is of great interest to the automotive industry due to the excellent combination of strength and toughness and mechanical properties [26]. As a result, the UTS of the sample treated under these conditions showed resistance values $>800 \mathrm{MPa}$ and a deformation of $\sim 30 \%$ (see Figures 7), such that the behavior is due to the effect of the constituents; on the one hand, a ferritic matrix that guarantee ductility and, moreover, homogeneously distributed martensite islands provide excellent resistance. In summary, the applied heat treatments show mechanical properties superior to those required according to the standard; therefore, the choice of any of them could perform satisfactorily. However, the TT5 and TT4 heat treatments are appropriate according to the application for which the material is intended.

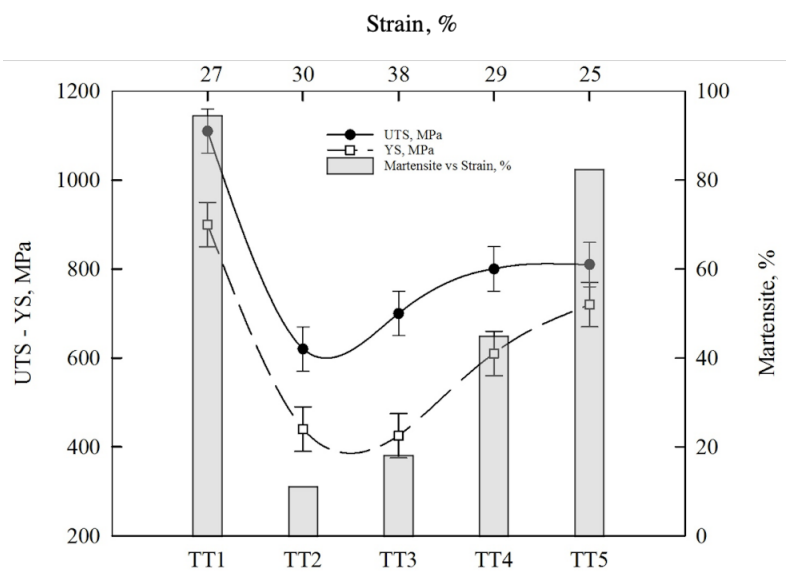

Fig. 7. Effect of heat treatment on mechanical properties and its relationship with the percentage of martensite. TT, thermal treatment; UTS, ultimate tensile strength; YS, yield strength.

\section{Conclusions}

1. The heat treatment applied allowed to increase the UTS above the minimum necessary according to the API standard for the manufacture of pipelines transmission. However, in the case of TT2, TT3, and TT4, the resulting microstructures must be treated with caution in the welding stages of steel processing since they could decrease the UTS in the thermally affected zones due to the phase transformation.

2. The quenching in water (case TT1) produced UTS values above $1,100 \mathrm{MPa}$ due to the presence of martensite which generates high hardness; how- 
ever, its high percentage significantly affects ductility.

3. The appropriate treatment to obtain a satisfactory combination of mechanical properties is quenching and partition (TT5), due to the existence of martensite and austenite, since, on the one hand, martensite raises the UTS value above 800 $\mathrm{MPa}$ without affecting other properties, while the austenite during the welding stage can transform into some decomposition product, allowing the mechanical properties to be maintained.

4. The dual-phase steel obtained (ferritemartensite) in the TT4 has suitable mechanical characteristics (UTS $800 \mathrm{MPa}$ ), despite its low carbon content. Although not the advisable option for this type of application, recently, these steels are of great importance for the automotive industry due to the excellent combination of strength and ductility.

The designed heat treatments generated microstructures where it was difficult to determine the constituents present by means of OM and SEM, so the EBSD technique using the analysis IQ data proved to be an excellent option to distinguish and quantify the resulting micro-constituents. In this work, it was possible to establish a procedure to raise the UTS of this steel, despite it being in the minimum range of the carbon content for X80 steels.

\section{Acknowledgments}

The authors want to acknowledge to the TecNM-ITM, CATEDRAS-CONACyT, AHMSA, Dr. Emmanuel Gutiérrez Castañeda of UAP and SNI for the permanent support to the academic groups of Modeling of Metallurgical Processes and Thermofluids.

\section{References}

[1] Farhat H, Oguocha INA, Yannacopoulos S. Effect of welding speed on weld quality and microstructure of tandem submerged arc welded X80 pipeline steel. In: Materials Science and Technology, 2009 Conference and Exhibition, Pittsburg, 2009, p. 2457.

[2] Nishioka K, Ichikawa K. Progress in thermomechanical control of steel plates and their commercialization. Sci Technol Adv Mater. 2012; https : //doi.org/10. 1088/14686996/13/2/023001
[3] Byoungchul H, Young MK, Sunghak L, Nack K. Correlation of rolling condition, microstructure, and low temperature toughness of X70 pipeline steels. J Metall Mater Trans A. 2005; https://doi.org/10.1007/ s11661-005-0043-1

[4] Rodrigues PCM, Pereloma EV, Santos DB. Mechanical properties of an HSLA bainitic steel subjected to controlled rolling with accelerated cooling. Mater Sci Eng A. 2000; https://doi.org/10.1016/ S0921-5093 (99) 00795-9

[5] Kong J, Zhen L, Guo B, Li P. Influence of Mo content on microstructure and mechanical properties of high strength pipeline steel. Mater Design. 2004; https: //doi.org/10.1016/j.matdes.2004.03.009

[6] Pouraliakbara H, Khalajb G, Jandaghia MR, Khalajb MJ. Study on the correlation of toughness with chemical composition and tensile test results in microalloyed API pipeline steels. J Min Metall Sect B Metall B. 2015; https://doi.org/10.2298/JMMB140525025P

[7] Faizabadi MJ, Khalaj G, Pouraliakbar H, Jandaghi MR. Prediction of toughness by using chemical composition and tensile properties in microalloyed line pipe steels. Neural Comput Appl. 2014; https://doi.org/10. 1007/s00521-014-1687-9

[8] Wang X, Xiao F-R, Fu Y-H, Chen X-W, Liao B. Material development for grade X80 heavy-wall hot inductions bends. Mater Sci Eng A. 2011; https : //doi .org/10. 1016/j.msea. 2011.10.017

[9] Goldenstein H, Gorni A, González Ramírez MF, Landgraf FJG. Caracterización y Análisis de la Evolución del Microconstituyente MA en Aceros Microaleados para Tubo API X80 Tratado Térmicamente. In: IX Congreso Iberoamericano de Ingeniería Mecánica, São Paulo, 2009; 60.

[10] Huda N, Midawi ARH, Gianetto J, Lazor R, Gerlich AP. Influence of martensite-austenite (MA) on impact toughness of X80 line pipe steels. Mater Sci Eng. 2016; https://doi.org/10.1016/j.msea.2016.03.095

[11] Niu J, Qi L-H, Liu Y-L, Ma L, Feng Y-R, Zang J-X. Tempering microstructure and mechanicals properties of pipeline steel X80. Trans Nonferr Met. Soc China. 2009; https://doi.org/10.1016/ S1003-6326(10)60111-2

[12] Liu Y-J, Li Y-M, Huang B-Y. Influence on austenitizing temperature on apparent morphologies of asquenched microstructures of steels. J Cent South Univ Technol, 2006; https://doi.org/10.1007/ s11771-006-0142-1

[13] Bhadeshia H. Steels: microstructure and properties. 3rd ed. New York: Elsevier; 2006.

[14] Zhao J, Hu W, Wang X, Kang J, Cao Y, Yuan G, Di H, Misra RDK. A novel thermo-mechanical controlled processing for large-thickness microalloyed $560 \mathrm{MPa}$ (X80) pipeline strip under ultra-fast colling. Mater Sci Eng A. 2016; https://doi.org/10.1016/j.msea . 2016.07.089

[15] López Granados NM. Estudio de las texturas de trans- 
formación de fase en aceros laminados en caliente para aplicaciones automotrices. Doctoral thesis, México, 2015, p. 58.

[16] Han SY, Shin SY, Lee S, Kim NJ, Bae J-H, Kim K. Effects of Cooling Conditions on Tensile and Charpy Impact Properties of API X80 Linepipe Steels. Metall Mater Trans A. 2010; https://doi.org/10.1007/ s11661-009-0135-4

[17] Sun XJ, Yuan SF, Xie ZJ, Dong LL, Misra RDK. Microstructure-property relationship in a high strengthhigh toughness combination ultra-heavy gauge offshore plate steel: The significance of multiphase microstructure. Mater Sci Eng A. 2017; https://doi.org/10. 1016/j.msea. 2017.02.058

[18] Tottenn GE. Steel heat treatment: metallurgy and technologies. 2nd ed. Oregon: CRC Press; 2007.

[19] Schwarts AJ, Kumar M, Adams BL, Field DP. Electron backscattering diffraction in material science. 2nd ed. New York: Springer; 2000.

[20] Tarasiuk J, Gerber P, Bacroix B. Estimation of recrystallized volume fraction from EBSD data. Act Mater. 2002; https://doi.org/10.1016/ S1359-6454 (02) 00005-8

[21] Humphreys FJ. Review grain and subgrain characterization by electron backscatter diffraction. J Mater Sci. 2001; https://doi.org/10.1023/A: 1017973432592

[22] Lassen K. Automatic high-precision measurements of the location and width of Kikuchi bands in elec- tron backscatter diffraction patterns. J Microsc.1998; https://doi.org/10.1046/j.1365-2818.1998. $00330 . x$

[23] Wilson AW, Spanos G. Application of orientation imaging microscopy to study phase transformations in steels. Mater Charact. 2001; https://doi.org/10.1016/ S1044-5803(01)00140-1

[24] Wu J, Wray PJ, Garcia CI, Hua M, DeArdo AJ. Image quality analysis: A new method of characterizing microstructures. ISIJ Int. 2005; https://doi.org/10. 2355/isijinternational.45.254

[25] Lopez Granados NM, Salinas Rodriguez A. EBSD Investigation on Effect of Cooling Rate on Microstructure and Transformation Textures of High Strength Hotrolled Steel Plates. J Iron Steel Res Int. 2016; https : //doi .org/10.1016/S1006-706X (16) 30043-7

[26] Barella S, Venturini R, Mapelli C. Crystallographic texture and mechanical properties in high martensitic dual phase steels In: The 1st. International Conference SuperHigh Strength Steels, Italy, 2005.

[27] Wilson AW, Madison JD, Spanos G, Determining phase volume fraction in steels by electron backscattered diffraction. Scr Mater. 2001; https://doi.org/10. 1016/S1359-6462(01)01137-X

Received 23-02-2021

Accepted 08-05-2021 